\title{
The Evidence for Prosthodontic Treatment Planning for Older, Partially Dentate Patients
}

\author{
Ridwaan Omar \\ Department of Prosthetic Dental Sciences, College of Dentistry, King Saud University, Riyadh, Saudi Arabia
}

\author{
Key Words \\ Prosthodontics · Prosthetic dentistry - Treatment needs \\ and decisions - Limiting treatment goals $\cdot$ Shortened \\ dental arch $\cdot$ Evidence-based practice
}

\begin{abstract}
This paper provides a review of the available evidence for traditional prosthodontic need determination and management strategies for older, partially dentate individuals, and compares it to the documented functional benefits of a more limited yet targeted approach to alleviating morphological shortfalls for this group of people, at the population level. The reasons for which the traditional total replacement strategy is not universally applicable or viable are discussed, and research is presented which tests many of the assertions made for the mandatory replacement of posterior teeth. Evidence is presented of the growing prosthodontic challenge posed by an increasing number of middle-aged and older partially dentate individuals in society: many of their remaining teeth are in poor condition, yet few such patients are willing to accept the prospect of becoming edentulous. The shortened dental arch concept is discussed and proposed as an appropriate strategy when complex intervention is to be avoided, inadvisable, or not possible. At the population level, current evidence suggests that prosthodontic strategies aimed at the restoration and/or
\end{abstract}

replacement of all lost molars may be inappropriate in older, partially dentate individuals. A more limited yet targeted strategy is both more effective and more efficient, and should not be seen as compromised care.

Copyright @ 2003 S. Karger AG, Basel

\section{Introduction}

Adult dental health continues to improve in a number of industrially developed countries [1-3]. From a prosthodontic perspective, patterns of tooth loss are changing, with steady reductions in the numbers of edentulous individuals [4, 5], and accompanying increases among older age groups of those who are partially dentate $[2,5]$. Since these people would have experienced higher disease levels historically, many of the retained teeth would already have been restored [3]. Against this background of changing dental demographic profiles, there are also changes in population demographics [6], culminating in a larger proportion of ageing, dentate people. But being dentate is an advantage in terms of oral functional benefits only if the inherent risks of a few poorly distributed, perhaps structurally and/or biologically compromised teeth can be minimised [7]. At the same time, fewer of these individuals are willing to accept their partially dentate condition as a natural prelude to edentulism.

Prof. Ridwaan Oma

Department of Prosthetic Dental Sciences

College of Dentistry, King Saud University

PO Box 60169, Riyadh 11545 (Saudi Arabia)

Tel./Fax+9661488 5241, E-Mail romar.ksa@zajil.net 
The challenges for prosthodontic treatment planning so posed are further compounded by the differences in dental health that exist both within $[8,9]$ and between countries [10]. Prosthodontic treatment of depleted, broken-down dentitions varies widely, but the replacement of missing teeth has traditionally been its cornerstone. That the patient benefits from such an approach at an individual level cannot be disputed. Yet at the population level, and especially so amongst the growing numbers of middle-aged and older partially dentate patients, such an approach has limited applicability [11]. Molars are the teeth most affected by disease, with $85 \%$ of them either missing, decayed, unsound or restored, according to a survey conducted in the United Kingdom [9]. Restoration and/or replacement of such teeth, often of a repetitive nature, must include a consideration of the high initial cost of treatment, its cost-effectiveness, longevity and repairability. For these reasons, as well as medical and physical constraints, it is necessary that a patient's functional needs be more realistically and precisely defined. In this way, interventions might be more purposefully designed to achieve more effective and efficient long-term outcomes.

In this review, the ways in which the partially dentate patient has been customarily evaluated and managed are described, and evidence is presented relating to the rationale, execution and clinical outcome. Substantive research findings, with special reference to the concept of the shortened dental arch (SDA) [12], are presented which suggest a reassessment of conventional treatment needs and goals. How the evidence might point the way to more appropriate management strategies for the growing number of ageing, partially dentate patients at the population level is considered.

\section{Conventional Prosthodontic Paradigms}

The primary aim of oral health care is the maintenance of a healthy, natural, functional dentition for life. The adult dentition is not a morphologically stable entity, being subject to continuous changes arising from physiological as well as pathological processes throughout life. An accumulation of such changes, due to a lack of preventive and restorative intervention, and generally as a function of increasing age, can lead to partial, and in some cases total, loss of teeth. A likely deterioration in oral function follows.

Dentistry has sought to reverse any threats to the integrity of the dentition by applying prosthodontic solutions in the belief that a loss of arch intactness would result in a reduction in oral health. This traditional therapeutic model gave rise to the '28-tooth syndrome', which dictated the need for complete dental arches, i.e. 28 teeth, 14 in each arch [13]. Such a state of completeness ensured, or at the very least contributed to, optimal health by providing occlusal stability through maximal bilateral intercuspal tooth contacts. In this way, treatment needs were invariably shaped by the imperative for total tooth replacement, failure of which would almost certainly result in occlusal instability (and occlusal discrepancies), risk of temporomandibular disorders (TMD), and reduced chewing ability.

Within the mechanical framework described, an idealised morphological template was used to evaluate the acceptability of an existing occlusion. It was also the blueprint upon which the planned future occlusion was designed. Several other mechanical axioms evolved, including the beliefs that any overload of the system has to be avoided [14], and that teeth with increased mobility pose a risk to a positive overall prognosis [15]. Not surprisingly, for many years much of the prosthodontic research focused on how to optimise the technology for fabricating prostheses. In contrast, little attention was given to the actual therapeutic goals that were being sought through the application of the said technology [16].

\section{The Evidence for Tooth Replacement Strategies}

If there were generally little risk attached to prosthetic tooth replacement, the options for treatment would be largely a matter of personal choice, both for the patient and the provider. Since risks are known to exist, the decision-making process must take into account the effectiveness and efficiency of the available treatment options. This is particularly pertinent for older, partially dentate patients, who are more likely to experience complications arising from a history of repeat restorations [17] as well as various barriers to treatment.

Traditionally, clinical decision-making comprised an exchange in which the patient expressed a complaint and the provider gave advice, made a decision, and provided treatment, after considering all the factors and intuitively allowing the process to be influenced by similar past experiences [18]. The process is prone to wide variations, which affects the quality of care [19]. In contrast with the old standard of 'commonly accepted practice', the new model for decision-making is based on the concept of evidence-based practice [20]: while still starting with the 
patient's problem, any uncertainty about its solution is overcome by converting the problem into an answerable question. The best current literature relating to the question is identified and critically appraised for its validity and applicability to the given clinical condition, and a decision reached [18]. While clinical judgement must remain an integral part of fully informed decision-making, it cannot afford to ignore the evidence. The ways in which scientific evidence has influenced the definition of functional needs and the derivation of prosthodontic treatment goals are reviewed in the following subsections.

\section{Tooth Loss and Occlusal Instability}

In 1937, Hirshfeld [21] listed the series of events that could follow the loss of a single lower first molar, which was seen as concrete support for the concept of arch integrity (fig. 1). As a result of tooth movement, there would be loss of stable, supporting tooth contacts, possible loss of occlusal vertical dimension, and functional problems including occlusal interferences, especially of the non-working type. This has been, and to a large extent remains, the prevailing view.

Research evidence on the subject has been contradictory, with one study reporting that very few unopposed teeth supraerupted over 5 years [22], and another that all unopposed teeth had supraerupted over periods of up to 15 years [23]. Recently, it was reported that molars which were documented as unopposed for periods longer than 10 years did not all supraerupt: one fourth of the sample supraerupted by more than $2 \mathrm{~mm}$ beyond the occlusal plane, and the rest by less than $2 \mathrm{~mm}$ or not at all; teeth losing antagonists after 26 years of age had a lower risk of supraeruption (fig. 2) [24]. It follows that the sequelae of tooth loss show wide individual variation, due to local and systemic factors, with potentially positive or negative influences and with known or unknown effects [25].

Loss of all or most of the posterior teeth has traditionally been considered a significant risk for occlusal instability, giving rise to extensive and uncontrolled migration of teeth, and leading to posterior bite collapse, overclosure and further breakdown of the dentition [26]. In follow-up studies over 9 years [27,28], researchers investigated the stability of the SDA, which consists of 20 teeth (fig. 3) [12]. Based on a number of occlusal indicators, including intercuspal occlusal contact, anterior tooth relationships, interdental spacing, occlusal wear and alveolar bone levels, durable occlusal stability was confirmed, with initial minor changes being characterised as self-limiting and adaptive. No contribution to occlusal stability was gained

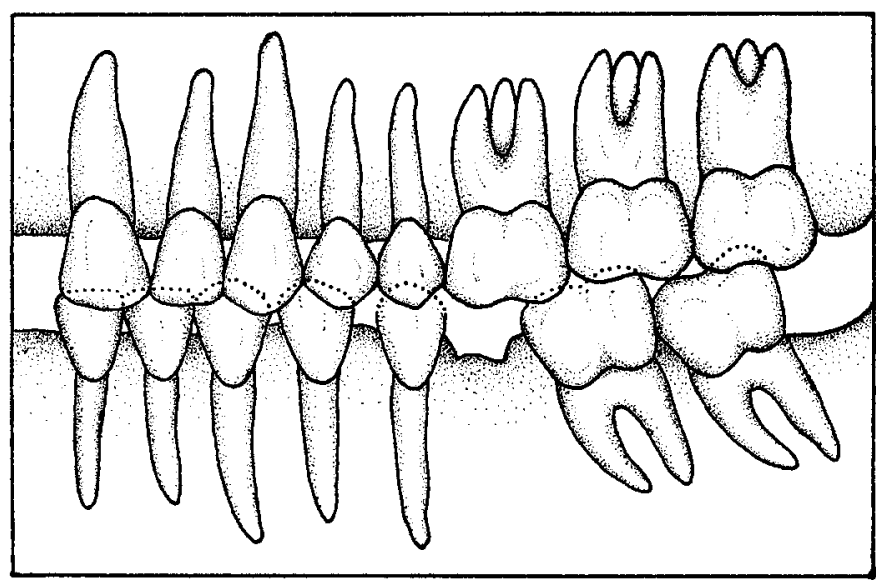

Fig. 1. Potential instability following loss of a lower first molar: migration in the form of tipping, rotation and supraeruption; opening of proximal contacts leading to food impaction; uneven marginal ridges; occlusal interferences; alveolar bone loss at the site of the lost tooth [after ref. 21].

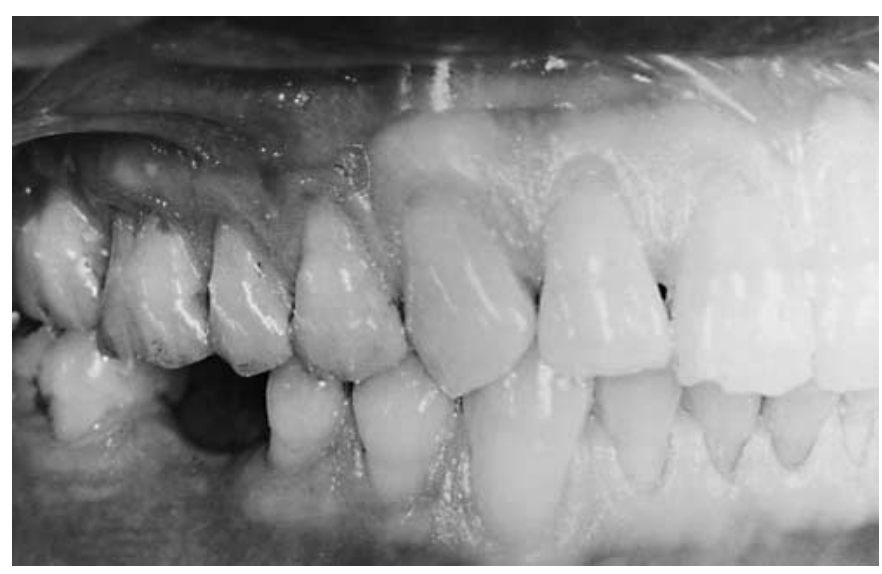

Fig. 2. A 59-year-old man who lost his lower right first molar more than 10 years previously; there is little sign of migration or supraeruption of teeth.

from the use of removable partial dentures (RPD), and there was no continuing periodontal breakdown as long as any pre-existing periodontal condition had been treated.

In summary:

(1) The consequences of posterior tooth loss show wide individual variation and are at least partly predictable, which suggests a management strategy of wait-and-see as opposed to mandatory immediate replacement.

(2) The risks of bite collapse, and the consequent need for interceptive prosthodontic therapy to replace molars in SDA patients, are unsupported. 


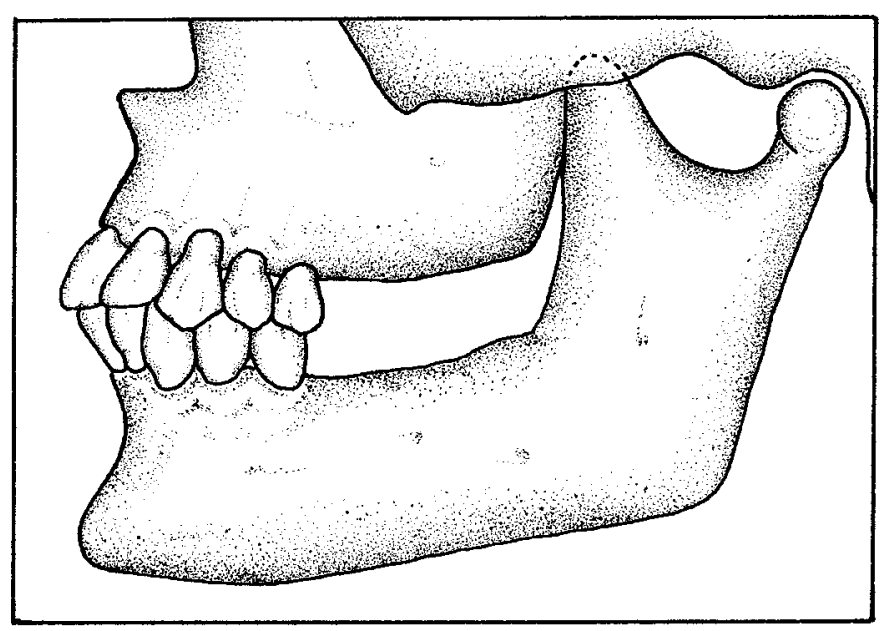

Fig. 3. SDA, up to and including the second premolars [after ref. 12].

\section{Tooth Loss, Occlusal Instability and Bruxism}

Occlusal disharmony was believed to precipitate bruxism [29], which, in turn, could be relieved by occlusal modification [30]. Since occlusal instability arising from tooth loss was at one time considered a likely cause of occlusal disharmony [26], missing teeth were replaced in order to treat, or indeed prevent, bruxism. However, nocturnal bruxism is an innate activity of central origin [31], which may be classified as a stress-related sleeping disorder [32, 33].

Although research has failed to show any lasting harmful effects caused by bruxism in healthy individuals [34], excessive occlusal wear can occur in some cases, which may require prosthodontic correction [35]. The management of tooth wear, which usually has a multifactorial aetiology [36], can present a difficult challenge.

\section{In summary:}

(1) Occlusion is not currently considered to be amongst the essential aetiological factors for bruxism, and thus there is no place for occlusal therapy, including prostheses, in its prevention or treatment.

(2) In cases of advanced occlusal wear, treatment should be limited to solving specific problems, although this may very well indicate extensive reconstruction in some cases [37].

\section{Tooth Loss and TMD}

Loss of molar support was believed to be an aetiological factor in TMD, which led to the strategy of replacing molars in order to prevent as well as treat the condition. However, research findings do not support such a notion [38-40]. Neither has an increased risk for TMD, or a tendency for more signs and symptoms to develop with time, been observed in SDA patients [41]. Aside from this, the observed correlation between osteoarthrosis of the temporomandibular joints and lack of molar support is confounded by the fact that increasing age is common to both tooth loss and degenerative changes of the temporomandibular joints [42]. Thus, any presumed cause-effect relationship is minimal when adjusted for age [34].

Besides loss of molar support, occlusal discrepancies have also been considered to be of aetiological significance in TMD [43]. Although the evidence for such an association is either weak or non-existent [34], there may be some circumstantial evidence that occlusal discrepancies play a predisposing role.

\section{In summary:}

(1) Currently, it would appear that the capacity of the masticatory system to adapt to tooth loss is great, and does not warrant replacement on preventive grounds alone.

(2) In general terms, given the known potential for prostheses to provoke sudden changes, it would be prudent to exercise caution when considering prosthodontic therapy in a patient, who, at the time of planned intervention, has signs and symptoms of TMD.

(3) While prosthodontic treatment might be indicated in patients with loss of teeth together with occlusal discrepancies, it cannot be promoted as a method of preventing or treating TMD, and certainly not as an alternative for failed conventional treatment of TMD.

\section{Tooth Loss and Chewing Ability}

Objectively assessed chewing efficiency, using test foods for example, decreases almost linearly with the number of remaining occluding teeth [44-46]. Under simulated SDA conditions, chewing efficiency was similarly reduced with decreasing number of post-canine teeth [47]. However, there is no such clear correlation between a reduced posterior occlusion and patient-perceived masticatory ability. Most reports confirm that 20 well-distributed teeth provide adequate chewing function [48-50]. In a group of older adults, eating satisfaction was reported with 21 or more remaining natural teeth, 2 or more contacting pairs of posterior teeth, and no RPD [7]. Furthermore, the risks associated with RPDs, especially distal extension types, in the absence of meticulous oral hygiene measures are well known [51, 52]. This, together with their instability due to alveolar ridge resorption [53] and a feeling of discomfort, which discourages patients from wearing them $[54,55]$, weigh against their use for the replacement of missing posterior teeth, especially in older patients $[7,56]$.

\section{In summary:}

(1) Objective tests show that chewing efficiency decreases in relation to the number of remaining occluding teeth. 
(2) Subjectively, there is no such correlation for reported chewing ability, with chewing satisfaction generally reported with 20 or more remaining teeth.

(3) Distal extension RPDs do not contribute to subjective chewing ability.

\section{Further Considerations in the Assessment of Treatment Need}

Much of what has been discussed so far has related to so-called objective assessments of patients' prosthodontic needs, the basis of which is that the reconstitution of missing parts determines clinical success. The importance of this input into the decision-making process should not be devalued, yet there are other aspects that need to be considered. It is increasingly recognised that a successful long-term outcome also depends on fully defining the extent of a patient's functional impairment, and then identifying an effective and efficient means of addressing the resultant need.

Patient's perceptions of the consequences of their damaged and/or depleted dentitions, the degree of their resulting functional impairment, and the extent to which the treatment addresses their problems are also important. Such subjective assessments are generally substantially lower than those made by professionals [57].

\section{Adaptation}

Many natural dentitions deviate from the criteria used to define a physiologic occlusion, yet appear to be healthy [58]. The inconsistency is explained on the basis of the adaptive capacity of the individual. Any disruption of morphological integrity is accompanied by either a greater, or lesser, but generally unpredictable, degree of adaptation for the maintenance of satisfactory function, or leads to a non-physiologic state. Prosthodontic therapy seeks to counteract the challenges to the patient's adaptive ability, as well as to avoid itself becoming an additional challenge to adaptive ability. Adaptive responses take time to manifest. Thus, since the perceived need for tooth replacement is greatest immediately following tooth loss and then subsides [59], and secondary morphological changes following tooth loss are frequently self-limiting [28], it is important to adopt a wait-and-see approach in the process of determining treatment need.

In summary:

(1) Adaptation influences the degree of functional impairment.

(2) Morphological deficits alone are therefore of limited value in determining a patient's treatment need.

\section{Patient-Perceived Needs and Outcomes}

Patient demand for replacement of missing posterior teeth is relatively weak $[60,61]$. A comprehensive review of patients' satisfaction with their oral status and perceived need for treatment showed that aesthetics play a far stronger role in determining need than does chewing function, and that 20 or more 'well-distributed' teeth provided sufficient chewing ability; in people over 45 years of age, such an arrangement satisfied their needs in relation to both appearance and function [62]. This consensus dovetails well with the SDA concept [28].

The primary reason for which patients request crowns is aesthetic improvement $[63,64]$, and they request fixed partial dentures (FPD) to replace unsatisfactory or failed prostheses [63]. The level of patients' satisfaction with treatment correlates with the degree to which their demands or expectations are met [65]. Patient-based assessments of treatment outcomes have been advocated as a means to gain more substantive information on the effect of oral disorders on health-related quality of life [66]. Thus, people expect their forthcoming prosthodontic treatment to enhance their sense of wellbeing, which may arise from a perception that oral functional status can be linked to general health [67].

In summary:

(1) Patient demand for posterior tooth replacement is relatively weak

(2) Patients' satisfaction with treatment depends on their expectations being met.

\section{Treatment Efficiency and Longevity}

Well-controlled clinical studies have shown that patients provided with properly designed RPDs wear their dentures and are satisfied with the results [53]. In population surveys, however, RPDs appear to be a mixed blessing. Although they serve an important function when replacing missing anterior teeth, their impact on eating ability and overall satisfaction when used to replace posterior teeth is generally not positive [7]. Fixed prostheses are accepted more favourably by patients, but also incur a short- and longer-term biological cost, as well as the risk of technical complications. In general practice settings, success rates of $65-68 \%$ after $15-20$ years have been reported for FPDs [68, 69], compared to 10-year survival rates of $50 \%$ for RPDs [55]. Secondary caries and mechanical failures are the most frequent reasons for further treatment, or for frank failure of FPDs [68-70]. FPDs with cantilever extension units have typically shown higher failure rates than conventional end-abutment designs [71, 72], although the difference is negligible in the longer term [69]. 
It has also been shown that patients with distal extension cantilever FPDs have better overall outcomes over 5 years compared to patients with distal extension RPDs [73]. Significantly fewer replacements and modifications, lower caries prevalence, better perceived function, and greater cost-effectiveness were observed for cantilever FPDs as compared to RPDs, and could be a preferred prosthodontic option in selected posterior distal extension cases. At the population level, however, such solutions are inapplicable, while the demand for RPDs will be triggered only when a considerable number of posterior teeth have been lost [74]. In general, if an older patient has enough wellpositioned natural teeth to provide adequate eating, anterior aesthetics would be best restored using simple anterior FPDs rather than RPDs, provided that this can meet the patient's aesthetic needs.

In summary:

(1) Properly designed and maintained RPDs provide good patient satisfaction.

(2) In population surveys, FPDs are more universally acceptable to patients than RPDs.

(3) In older, partially dentate patients who have adequate chewing ability, it is best to treat anterior spaces with simple FPDs.

\section{Collating the Evidence}

The blueprint guiding prosthodontic planning is gradually transforming itself from one in which professionally perceived morphological shortfalls drive prosthodontic treatment, to one in which patient-perceived functional impairment plays a more central role. However, the adoption of evidence-based therapeutic options varies amongst clinicians, which could conceivably give rise to the apparent idiosyncrasies of decision-making. Surveys of dentists' attitudes towards treatment needs, in the presence of unfolding evidence, have produced interesting results. On the question of the risk of supraeruption of unopposed teeth, a large majority of dentists felt the risk was high, and cited this as a reason for replacing missing teeth; the group was equally divided between immediate replacement and observation [75]. Most of the dentists who were asked about their attitutes towards the SDA concept agreed with it; fewer had managed a small number of patients with the strategy, although some felt that prosthetic extension of the arches was sometimes needed $[76,77]$.

In many ways, the growing number of older, partially dentate individuals presents a mounting challenge for prosthodontic management. On the one hand, fewer of these patients are willing to accept the prospect of edentulism. On the other hand, in the midst of shrinking health care budgets, there are increasing demands from authorities and patients alike for cost-effectiveness and efficiency in the treatments prescribed. Clearly, whenever feasible, the ideal of a complete dentition must remain. Yet such a goal might neither be attainable for general, dental or financial reasons, nor indeed be necessary [11]. When constraints apply, priorities need to be set, and the World Health Organization has adopted as a goal the maintenance of 20 functioning teeth without the need for a prosthesis [78]. While there is much individual variation in the minimum number of teeth required for adequate function, the 20-tooth threshold is valid at the population level [11]. Thus, strategies aimed broadly at meeting such a functional target would seem to be appropriate.

\section{The SDA Concept}

Classically, the SDA occlusion consists of 20 teeth (all upper and lower incisors, canines and premolars) (fig. 3). In practice, strict conformity with this arrangement is unlikely due to the obvious variability in patterns of tooth loss. In the foregoing review, much of the research relating to SDA has already been described, and confirms the achievement of occlusal stability and satisfactory levels of oral function without undue effects [11]. The management strategy adopted is one that prioritises treatment goals when there is a need to simplify a complex treatment plan. This is accomplished by directing resources and treatment efforts towards preservation of the functionally strategic and sustainable region of the dentition, namely the anterior and premolar teeth. Molars, which are at a high risk for dental disease and are generally lost earlier than other teeth $[9,79]$, receive a lower priority for restoration and therefore retention. Thus the quantity, complexity, and expense of treatment in the molar regions can be reduced, along with the associated higher risks of failure [80]. All available maintenance and restorative care can be targeted towards the anterior and premolar region of the dentition. A prerequisite would be that the latter teeth should have a good prognosis, and any major problems, such as caries, periodontal disease, and severe tilting/drifting as a result of discontinuous arches, should be confined mainly to the molar region.

Essentially, the SDA strategy seeks to provide a functionally adequate dentition for middle-aged or older adults with a history of compromised oral health. Highrisk younger individuals, who absorb disproportionately large amounts of health care budgets [81], are also potential candidates for such an approach, although an occlu- 
sion up to the first molars, or 8 occlusal units (molars counting as 2 units), is then recommended [25]. In complex treatment plans, the SDA approach offers the alternative of less treatment, which is also less complicated, less time-consuming and less expensive. Whether or not the results are inferior to that of the full-scale reconstructive approach has not been demonstrated. Indeed, as regards accepted prosthodontic reconstructive methods, there is no conclusive evidence on the relative merits of the various methods of occlusal reconstruction, or the superiority of one occlusal scheme over another [82]. Neither is there any evidence on the superiority of technically sophisticated methods over simpler ones. A long-term follow-up of patients treated with cross-arch FPDs showed that various occlusal factors, such as occlusal contact pattern, number and intensity of occlusal contacts, and centric relation-intercuspal position relationship, had no significant influence on subjective function [83]. Similar findings were reported for mandibular implant-supported fixed prostheses opposing maxillary complete dentures [84]. It follows that many of the past rigid formulae for occlusal reconstruction, whose patient benefits were confidently presented as 'self-evident', lack scientific evidence, and are in serious need of objective evaluation. Nevertheless, any repositioning of the prosthodontic method as a result of credible new evidence should not imply a compromise of the principles of quality care.

The evidently deliberate limiting of treatment goals with an SDA approach prompts the question whether the mere absence of complaint about functional problems can be a justification for not trying to improve function by appropriate restoration [85]. An individualised patient management approach demands that such questions always be posed, as was the case in figure 4 . On the other hand, the SDA strategy aims to rationalise the management dilemmas that arise when constraints prevail, as was the case in figure 5 . Such issues are particularly pertinent at the population level, but not exclusively so.

\section{Conclusion}

Due to changes in patterns of dental disease and tooth loss, an increasing number of older adults have more teeth. However, these teeth have more restorations, which are often large and complex and require time as well as advanced skills to maintain. Traditional prosthodontic strategies for managing such a problem, whilst selectively applicable on an individual basis, may be both inadequate and inappropriate at the population level. The evidence
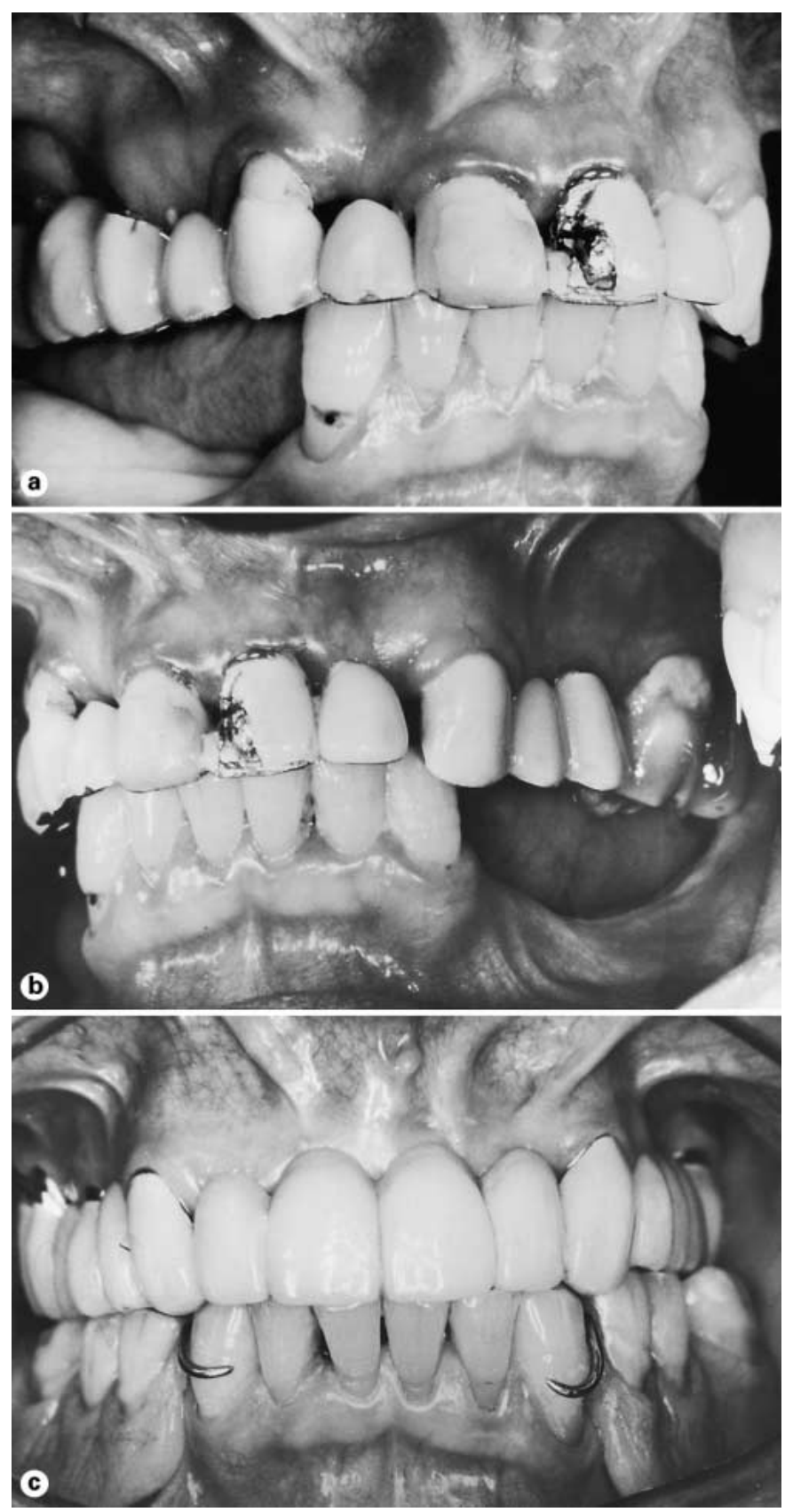

Fig. 4. a, b A 55-year-old woman who was unhappy about her appearance and lack of lower posterior teeth; the upper fixed prosthesis had failed with caries, non-vital teeth and loss of periodontal support at several sites. c Prosthodontic treatment comprised an upper full-arch metal-ceramic splint on 5 abutments with telescopic retainers and a lower distal extension RPD. 


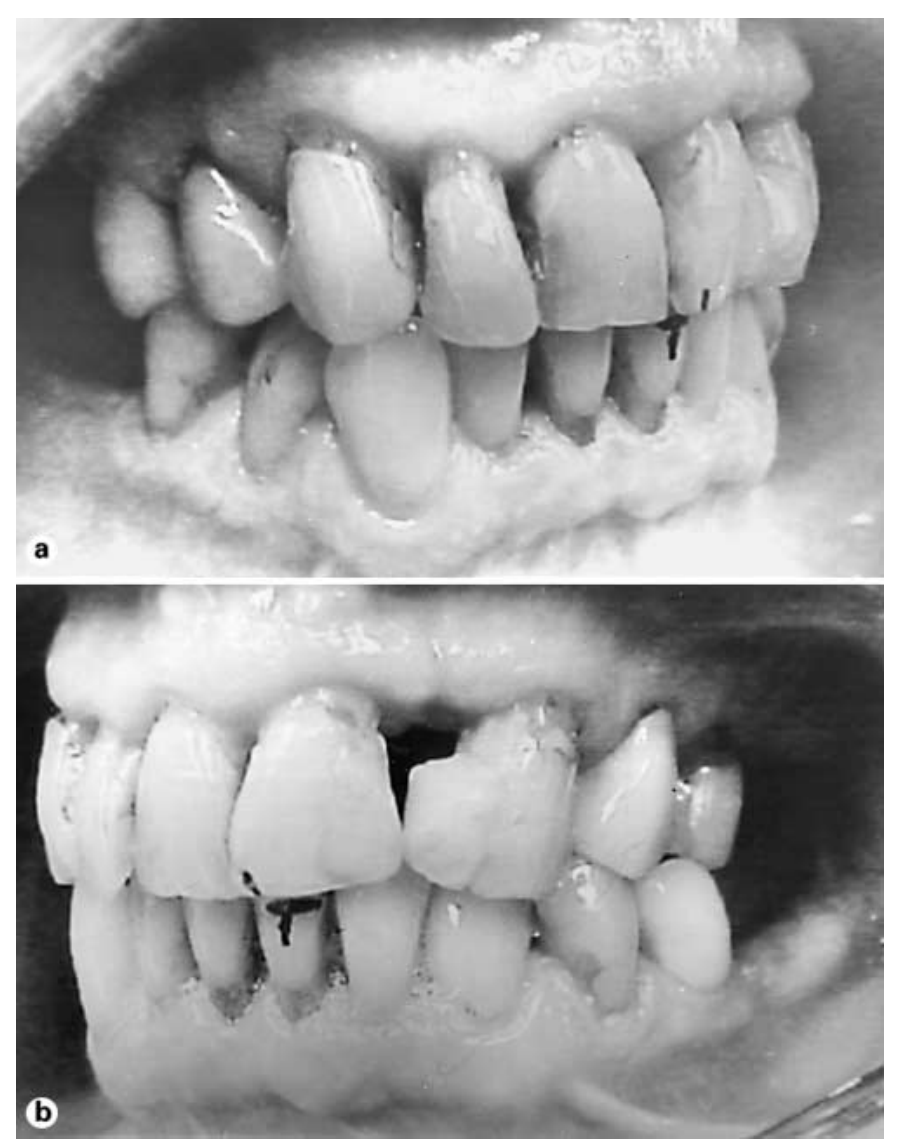

indicating that it is necessary to change the way in which clinicians plan and deliver treatment to reflect the new situation is compelling. Considerations of functional visà-vis morphological impairment should more strongly influence the nature of the treatment, in order to more definitively and accurately target patients' needs. Research has shown the relevance of the SDA concept for managing the older adult with a reduced, compromised dentition.

Fig. 5a, b. A 72-year-old man who had all his molars extracted 7 years previously at his request: he was worried that the amalgam restorations in his molars were 'poisoning' him and he was not content to have the restorations replaced with another material; there is no sign of instability of the resulting shortened dental arches, and neither is there any plan to provide prostheses to improve his chewing ability; the upper left lateral incisor was recently extracted for periodontal reasons and the space temporarily restored with composite resin; the marks on his teeth were made for the purpose of occlusal analysis (courtesy of Dr. Anders Johansson, Örebro, Sweden).

\section{References}

1 Eklund SA, Pittman JL, Smith RC: Trends in dental care among insured Americans: 1980 to 1995. J Am Dent Assoc 1997;128:171-178.

2 Österberg T, Carlsson GE, Sund V: Trends and prognoses of dental status in the Swedish population: Analysis based on interviews in 1975 to 1997 by Statistics Sweden. Arch Odontol Scand 2000;58:177-182.

3 Pine CM, Pitts NB, Steele JG, Nunn JN, Treasure E: Dental restorations in adults in the UK in 1998 and implications for the future. $\mathrm{Br}$ Dent J 2001;190:4-8.

4 Heath RM: The dental health of elderly people in Britain, 1968 to 1988 . Int Dent J 1992;42: 399-402.

5 Steele JG, Treasure E, Pitts NB, Morris J, Bradnock G: Total tooth loss in the United Kingdom in 1998 and implications or the future. Br Dent J 2000;189:598-603.

6 Davies AM: Epidemiology and the challenge of ageing. Int J Epidemiol 1985;14:9-21.

7 Steele JG, Ayatollahi SM, Walls AW, Murray $\mathrm{JJ}$ : Clinical factors related to reported satisfaction with oral function amongst dentate older adults in England. Community Dent Oral Epidemiol 1997;25:143-149.
8 Österberg T, Carlsson GE, Sund V, Fyhrlund A: Prognosis of and factors associated with dental status in the adult Swedish population 1975-1989. Community Dent Oral Epidemiol 1995;23:232-236.

9 Nunn J, Morris J, Pine C, Pitts NB, Bradnock $\mathrm{G}$, Steele J: The condition of teeth in the UK in 1998 and implications for the future. Br Dent $\mathbf{J}$ 2000;189:639-644.

10 Ettinger RL: Attitudes and values concerning oral health and utilization of services among the elderly. Int Dent J 1992;42:373-384.

11 Witter DJ, van Palenstein Helderman WH, Creugers NH, Käyser AF: The shortened dental arch concept and its implications for oral health care. Community Dent Oral Epidemiol 1999;27:249-258.

12 Käyser AF: Shortened dental arches and oral function. J Oral Rehabil 1981;8:457-462.

13 Levin B: The 28-tooth syndrome - or should all teeth be replaced? (editorial). Dent Surv 1974; $50: 47$.

14 Ante I: The fundamental principles of abutments. Mich State Dent Soc Bull 1926;8:1423.
15 Shillingburg HAT, Hobo S, Whitsett LD, Jacobi R, Brackett SE: Fundamentals of Fixed Prosthodontics, ed 3. Chicago, Quintessence, 1997 pp 89-93.

16 Jokstad A, Ørstavik J, Ramstad T: A definition of prosthetic dentistry. Int J Prosthodont 1998; 11:295-301.

17 Elderton RJ: Treating restorative dentistry to health. Br Dent J 1996;181:220-225.

18 Anderson JD: Need for evidence-based practice in prosthodontics. J Prosthet Dent 2000; 83:58-65.

19 Plasschaert AJ, Verdonschot EH, Wilson NH, Blinkhorn AS: Decision making in restorative dentistry: Intuition or knowledge based? $\mathrm{Br}$ Dent J 1995;178:320-321.

20 Sackett DL, Rosenberg WM, Gray JA, Haynes RB, Richardson WS: Evidence based medicine: What it is and what it isn't (editorial). BMJ 1996;312:71-72.

21 Hirshfeld I: The individual missing tooth. J Am Dent Assoc 1937;24:67-82.

22 Love WD, Adams RL: Tooth movement into edentulous areas. J Prosthet Dent 1971;25: 271-278. 
23 Compagnon D, Woda A: Supraeruption of the unopposed maxillary first molar. J Prosthet Dent 1991;66:29-34.

24 Kiliaridis S, Lyka I, Friede H, Carlsson GE, Ahlqwist M: Vertical position, rotation and tipping of molars without antagonists. Int J Prosthodont 2000;13:480-486.

25 Käyser AF: Limited treatment goals: Shortened dental arches. Periodontology 2000 1994;4:714

26 Stern N, Brayer L: Collapse of the occlusion: Aetiology, symptomatology and treatment. J Oral Rehabil 1975;2:1-19.

27 Witter DJ, de Haan AF, Käyser AF, Van Rossum GM: A 6-year follow-up study of oral function in shortened dental arches. Part I: Occlusa stability. J Oral Rehabil 1994;21:113-125.

28 Witter DJ, Creugers NH, Kreulen CM, de Haan AF: Occlusal stability in shortened dental arches. J Dent Res 2001;80:432-436.

29 Krogh-Poulsen WG, Olsson A: Occlusal disharmonies and dysfunction of the stomatognathic system. Dent Clin North Am 1966;11:627635.

30 Ramfjord SP: Bruxism, a clinical and electromyographic study. J Am Dent Assoc 1961;62: 36-58.

31 Rugh JD, Barghi N, Drago CJ: Experimental occlusal discrepancies and nocturnal bruxism. J Prosthet Dent 1984;51:548-553.

32 Rugh JD, Ohrback R: Occlusal parafunction; in Mohl ND, Zarb GA, Carlsson GE, Rugh JD (eds): A Textbook of Occlusion. Chicago, Quintessence, 1988, pp 249-261.

33 Attanasio R: Nocturnal bruxism and its clinica management. Dent Clin North Am 1991;35: 245-252.

34 Seligman DA, Pullinger AG: The role of functional occlusal relationships in temporomandibular disorders: A review. J Craniomandib Disord Facial Oral Pain 1991;5:265-279.

35 Johansson A, Omar R: Identification and management of tooth wear. Int J Prosthodont 1994 7:506-516.

36 Johansson A, Haraldson T, Omar R, Kilaridis $\mathrm{S}$, Carlsson GE: An investigation of some factors associated with occlusal tooth wear in a selected high-wear sample. Scand J Dent Res 1993;101:407-415.

37 Setchell DJ: Conventional crown and bridgework. Br Dent J 1999;187:68-74.

38 De Boever JA, Adriaens PA: Occlusal relationship in patients with pain-dysfunction symptoms in the temporomandibular joints. J Oral Rehabil 1983;10:1-7.

39 Mejersjö C, Carlsson GE: Analysis of factors influencing the long-term effect of treatment of TMJ-pain dysfunction. J Oral Rehabil 1984; 11:289-297.

40 Pullinger AG, Seligman DA, Gornbein JA: A multiple logistic regression analysis of the risk and relative odds of temporomandibular disorders as a junctive of common occlusal features. J Dent Res 1993;72:968-979.

41 Witter DJ, de Haan AF, Käyser AF, Van Rossum GM: A 6-year follow-up study of oral function in shortened dental arches. Part II: Craniomandibular dysfunction and oral comfort. J Oral Rehabil 194;21:353-366.
42 De Boever JA, Carlsson GE: Temporomandibular disorders and the need for prosthetic treatment; in Öwall B, Käyser AF, Carlsson GE (eds): Prosthodontics - Principles and Management Strategies. London, Mosby-Wolfe, 1996, pp 97-110.

43 Mohlin B, Kopp S: A clinical study of the relationship between malocclusions, occlusal interferences and mandibular pain and dysfunction. Swed Dent J 1978;2:105-112.

44 Bates JF, Stafford GD, Harrison A: Masticatory function: A review of the literature. III. Masticatory performance and efficiency. J Oral Rehabil 1976;3:57-67.

45 Helkimo E, Carlsson GE, Helkimo M: Chewing efficiency and state of dentition: A methodologic study. Acta Odontol Scand 1978;36: 33-41.

46 Luke DA, Lucas PW: Chewing efficiency in relation to occlusal and other variations in the natural human dentition. Br Dent J 1985;159: 401-403.

47 Al-Ali F, Heath MR, Wright PS: Chewing performance and occlusal contact area with the shortened dental arch. Eur J Prosthodont Rest Dent 1998;6:127-132.

48 Cushing AM, Sheiham A, Maizels J: Developing sociodental indicators: The social impact of dental disease. Community Dent Health 1986; 3:3-17.

49 Witter DJ, Cramwinckel AB, Van Rossum GM, Käyser AF: Shortened dental arches and masticatory ability. J Dent 1990;18:185-189.

50 Aukes JN, Käyser AF, Felling AJ: The subjective experience of mastication in subjects with shortened dental arches. J Oral Rehabil 1988; 15:321-324.

51 Berg E: Periodontal problems associated with use of distal extension partial dentures: A matter of construction? J Oral Rehabil 1985;12: 369-379.

52 Wright PS, Hellyer PM, Beighton D, Health MR, Lynch E: Relationship of removable partial denture use to root caries in an older population. Int J Prosthodont 1992;5:39-46.

53 Bergman B: Periodontal reactions related to removable partial dentures: A literature review. J Prosthet Dent 1987;58:454-458.

54 Rosenoer LM, Sheiham A: Dental impacts on daily life and satisfaction with teeth in relation to dental status in adults. J Oral Rehabil 1995; 22:469-480

55 Vermeulen AH, Keltjens HM, van't Hof MA, Käyser AF: Ten-year evaluation of removable partial dentures: Survival rates based on retreatment, not wearing and replacement. J Prosthet Dent 1996;76:267-272.

56 Witter DJ, van Elteren P, Käyser AF: The effect of removable partial dentures on the oral function in shortened dental arches. J Oral Rehabil 1989;16:27-33.

57 Viglid M: Benefit related assessment of treatment need among the elderly. Gerontology 1993;10:10-14.
58 Mohl ND: Diagnostic rationale: An overview; in Mohl ND, Zarb GA, Carlsson GE, Rugh JD (eds): A Textbook of Occlusion. Chicago, Quintessence, 1988, pp 179-184.

59 Bergendal B: The relative importance of tooth loss and denture wearing in Swedish adults. Community Dent Health 1989;6:103-111.

60 Liedberg B, Norlen P, Öwall B: Teeth, tooth spaces, and prosthetic appliances in elderly men in Malmö, Sweden. Community Dent Oral Epidemiol 1991;19:164-168.

61 Tervonen T, Knuuttila M: Prevalence of signs and symptoms of mandibular dysfunction among adults aged $25,35,50$ and 65 years in Ostrobothnia, Finland. J Oral Rehabil 1988; 15:455-463.

62 Elias AC, Sheiham A: The relationship between satisfaction with mouth and number and position of teeth. J Oral Rehabil 1998;25:649_ 661

63 Walton TR: A ten-year longitudinal study of fixed prosthodontics. 1. Protocol and patient profile. Int J Prosthodont 1997;10:325-331.

64 Oates AJ, Fitzgerald M, Alexander G: Patient decision making in relation to extensive restorative treatment. Part I: Characteristics of patients. Br Dent J 1995; 178:449-453.

65 Allen PF, McMillan AS, Locker D: An assessment of sensitivity to change of the oral health impact profile in a clinical trial. Community Dent Oral Epidemiol 2001;29:175-182.

66 Locker D, Slade G: Association between clinical and subjective indicators of oral health status in an older adult population. Gerodontology $1994 ; 11: 108-114$.

67 Hakestam U, Glantz E, Söderfeldt B, Glantz P-O: What do patients expect from extensive restorative treatment? Eur J Prosthodont Rest Dent 1996;4:53-57.

68 Glantz P-O, Niler K, Jendresen MD, Sundberg $\mathrm{H}$ : Quality of fixed prosthodontics after 15 years. Acta Odontol Scand 1993;51:247-252.

69 Lundquist E, Karlsson S: Success rate and failures for fixed partial dentures after 20 years of service. Part I. Int J Prosthodont 1998; 11:133138.

70 Hämmerle $\mathrm{CH}$, Ungerer $\mathrm{MC}$, Fantoni $\mathrm{PC}$, Brägger U, Bürgin W, Lang NP: Long-term analysis of biologic and technical aspects of fixed partial dentures with cantilevers. Int $\mathrm{J}$ Prosthodont 2000;13:409-415.

71 Randow K, Glantz PO, Zöger B: Technical failures and some related clinical complications in extensive fixed prosthodontics: An epidemiological study of long-term clinical quality. Acta Odontol Scand 1986;44:241-255.

72 Karlsson S: Failures and length of service in fixed prosthodontics after long-term function. Swed Dent J 1989;13:185-192.

73 Budtz-Jørgensen E: Prosthodontics for the Elderly: Diagnosis and Treatment. London, Quintessence, 1999, pp 89-92.

74 Basker R, O'Mullane DM: Removable prosthodontic service related to need and demand; in Öwall B, Käyser AF, Carlsson GE (eds): Prosthodontics: Principles and Management Strategies. London, Mosby-Wolfe, 1996, pp 223 235. 
75 Lyka I, Carlsson GE, Wedel A, Kiliaridis S: Dentists' perception of risks for molars without antagonists: A questionnaire study of dentists in Sweden. Swed Dent J 2001;25:67-73.

76 Allen PF, Witter DF, Wilson NH, Käyser AF: Shortened dental arch therapy: Views of consultants in restorative dentistry in the United Kingdom. J Oral Rehabil 1996;23:481-485.

77 Allen PF, Witter DJ, Wilson NH: A survey of the attitudes of members of the European Prosthodontic Association towards the shortened dental arch concept. Eur J Prosthodont Rest Dent 1998;6:165-169.

78 WHO Expert Committee: Recent Advances in Oral Health. World Health Organ Tech Rep Ser 826. Geneva, WHO, 1992.
79 Hujoel PP, Loë H, Anerud A, Boysen H, Leroux BG: Forty-five-year tooth survival probabilities among men in Oslo, Norway. J Dent Res 1998;77:2020-2027.

80 Chace R, Low SB: Survival characteristics of periodontally involved teeth: A 40-year study. J Periodontol 1993;64:701-705.

81 Öwall B, Käyser AF, Carlsson GE: Prosthodontics around the world; in Öwall B, Käyser AF, Carlsson GE (eds): Prothodontics: Principles and Management Strategies. London, MosbyWolfe, 1996, pp 9-19.

82 Thornton LJ: Anterior guidance: Group function/canine guidance - a literature review. J Prosthet Dent 1990;64:479-482.
83 Yi SW, Carlsson GE, Ericsson I, Wennström JL: Long-term follow-up of cross-arch fixed partial dentures in patients with advanced periodontal destruction: Evaluation of occlusion and subjective function. J Oral Rehabil 1996; 23:186-196.

84 Wennerberg A, Carlsson GE, Jemt T: Influence of occlusal factors on treatment outcome: A study of 109 consecutive patients with mandibular implant-supported foxed prostheses opposing maxillary complete dentures. Int J Prosthodont 2001;14:550-555.

85 Wright PS: The shortened dental arch - to restore or not (editorial). Eur J Prosthodont Rest Dent 1996;4:51. 